\title{
Parallel Olfactory Systems in Insects: Anatomy and Function
}

\author{
C. Giovanni Galizia ${ }^{1}$ and Wolfgang Rössler ${ }^{2}$ \\ 'University of Konstanz, 78457 Konstanz, Germany; \\ email: giovanni.galizia@uni-konstanz.de \\ ${ }^{2}$ University of Würzburg, Biozentrum, Zoology II, 97074 Würzburg, Germany; \\ email: roessler@biozentrum.uni-wuerzburg.de
}

\section{Key Words}

olfactory coding, olfactory glomeruli, antennal lobes, mushroom bodies, olfactory tracts, neuroanatomy

\begin{abstract}
A striking commonality across insects and vertebrates is the recurring presence of parallel olfactory subsystems, suggesting that such an organization has a highly adaptive value. Conceptually, two different categories of parallel systems must be distinguished. In one, specific sensory organs or processing streams analyze different chemical stimuli (segregate parallel systems). In the other, similar odor stimuli are processed but analyzed with respect to different features (dual parallel systems). Insects offer many examples for both categories. For example, segregate parallel systems for different chemical stimuli are realized in specialized neuronal streams for processing sex pheromones and $\mathrm{CO}_{2}$. Dual parallel streams related to similar or overlapping odor stimuli are prominent in Hymenoptera. Here, a clear separation of sensory tracts to higher-order brain centers is present despite no apparent differences regarding the classes or categories of olfactory stimuli being processed. In this paper, we review the situation across insect species and offer hypotheses for the function and evolution of parallel olfactory systems.
\end{abstract}


Parallel pathway: parallel neuronal projections forming separate streams from one processing area to the next processing levels

ORN: olfactory receptor neuron

Antennal lobe (AL): centers for primary processing of olfactory information in the insect brain

Glomeruli: spheroidal areas of condensed AL neuropil, functional units, and site of convergent input from ORN axons and synaptic interaction with LNs and PNs

MGC:

macroglomerular complex

Projection neuron (PN): AL output neuron that transfers olfactory information from the AL to higher-order processing centers in the $\mathrm{MB}$ and $\mathrm{LH}$ in the protocerebrum

APT: antennoprotocerebral tract

Mushroom body (MB): higher sensory association and learning and memory centers in the insect brain that receive mostly olfactory input, but also visual, tactile, and gustatory information

\section{INTRODUCTION}

Olfaction plays a key role in the survival and reproduction of most animal species. Compared with our knowledge on sensory processing in other sensory systems such as visual and auditory systems, however, olfactory coding and perception is far from being understood. This is due most likely to the complexity of the olfactory world, to the as yet largely enigmatic logic of the olfactory code, and to our limited knowledge about chemotopic maps in the brain. Information processing along parallel pathways is an important feature of most biological sensory systems, and analyzing the connectivity, function, and behavioral relevance of these parallel pathways is crucial for understanding sensory coding and perception in general. In the mammalian visual system, for example, magno- and parvocellular pathways from the lateral geniculate nucleus mediate different elemental properties of vision such as color and spatiotemporal patterns (60). These specializations of processing along multiple pathways differentially contribute to visual perception $(66,67)$. The visual system of insects is similarly divided into color- and motion-sensitive visual pathways, and a recent study in Drosopbila melanogaster further dissected parallel pathways of the motion sensitive subsystem (78).

Functional specializations of sensory processing within the olfactory system have been appreciated only recently. In mammals, there are at least four pathways: the main olfactory system, the vomeronasal system, the septal organ, and the Grueneberg organ (10). Furthermore, the olfactory bulb itself consists of two mirror image sensory maps (70), but their functional relevance remains unclear. In the main olfactory system of fish, axons of three types of olfactory receptor neurons (ORNs) converge to specific regions of the olfactory bulb and connect to separate sets of relay neurons that project along parallel tracts to the telencephalon (29). Behavioral experiments suggest that these parallel pathways mediate different biological information such as social cues, sex pheromones, and food odors. Different subsystems are also present in amphibians $(64,65)$.
Parallel systems have been well characterized in insects and are the topic of this review. One obvious subdivision within the antennal lobe (AL) represents the separation between pheromone-specific glomeruli, called the macroglomerular complex (MGC), and a set of ordinary glomeruli (35). In D. melanogaster, different sensilla types map onto specific groups of glomeruli in the $\mathrm{AL}(14,18)$. In $\mathrm{Hy}$ menoptera (bees and ants), subdivisions of input and output streams of the AL are apparent. Distinct clusters of olfactory glomeruli are innervated by different antennal sensory input tracts and specifically connected to multiple projection neuron (PN) output tracts (antenno-protocerebral tracts, APTs; see below and Figure 2 for different usage of tract nomenclature across species) that project to higher-order brain areas via the lateral (1)-APT, the medial $(\mathrm{m})$-APT, and three mediolateral (ml)-APTs $(1,47,119)$. Whereas a dual-output pathway to the mushroom bodies (MBs) from a hemilobe division in the AL via $\mathrm{m}-\mathrm{APT}$ - and 1-APT-associated glomeruli is most prominent and obvious in Hymenoptera, multiple tracts are present in most insects studied so far, suggesting that parallel olfactory processing is a common trait in insect olfactory systems (47).

In this review, we cover parallel systems from three points of view. First, we give a condensed overview of the insect olfactory system, emphasizing how, along the steps involved in olfactory processing, a separation into parallel systems is possible or feasible. Second, we review the current knowledge on (segregated) parallel systems that are related to specific odors, such as pheromones or $\mathrm{CO}_{2}$, as best understood in moths and flies. Third, we analyze (dual or multiple) parallel systems that, to our current knowledge, are not involved in a strict separation of particular odor qualities but might be involved in higher-order processing properties, as exemplified by $\mathrm{AL}$ output tracts across insect species and specifically in Hymenoptera, in which they are most prominent. We close with a general functional consideration of both segregated and dual parallel systems. 


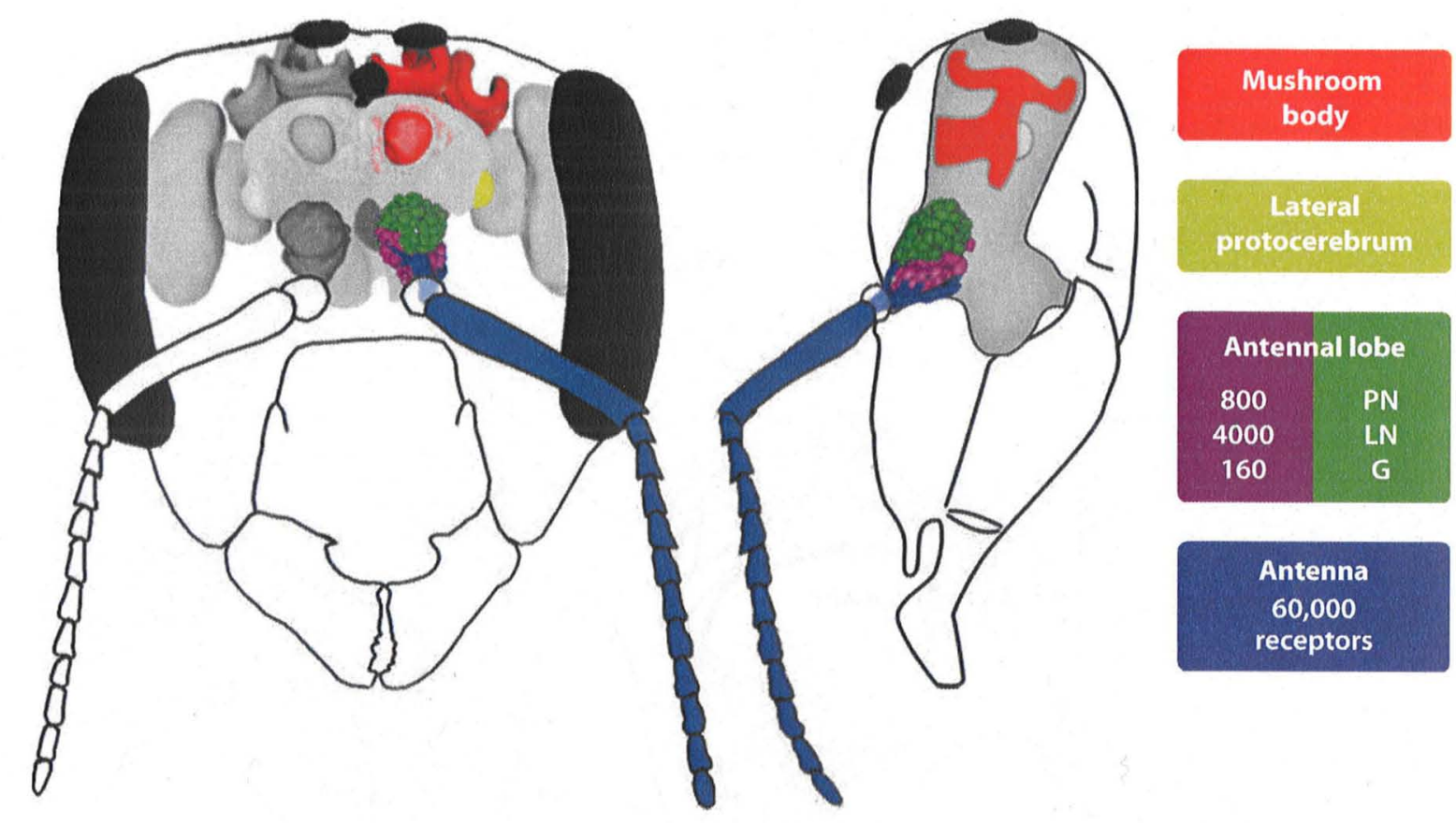

Figure 1

Overview of the honey bee olfactory system in a schematic head capsule (front and side views), with the main olfactory organs and areas (antenna, antennal lobe, lateral protocerebrum, mushroom body) indicated by colors. See text for details. Abbreviations: G, glomerulus; PN, projection neurons; LN, local neurons; receptors indicates receptor cells.

\section{BASIC STRUCTURE OF THE INSECT OLFACTORY SYSTEM}

A simplified view of the neural processing in olfactory information involves the following steps: receptor neurons, primary computation in the ALs, and then further processing in higher-order brain centers, such as the MBs or the lateral protocerebrum (Figure 1). In this section, we give a brief overview of this process, with particular emphasis on those places where functional segregation either occurs or is possible - a functional segregation that affords the evolution of parallel olfactory systems. See the following references for reviews on the olfactory system $(21,25,50,112,116)$.

\section{Different Sensilla}

ORNs are located and compartmentalized in olfactory sensilla, a situation that is fundamentally different from the uniform mucosa in mammals. Sensilla create at least four opportunities for parallel systems. First, sensilla differ in their morphological shape, including trichoid sensilla (hair-like), basiconic sensilla (peg-shaped), coeloconic sensilla (peg-shaped sensilla recessed in a pit), sensilla ampullacea (with a long internal duct), sensilla placodea (poreplate sensilla), and several other types. Several hypotheses exist for the structure-function relationship of this beautiful diversity: Long trichoid sensilla are ideal for the creation of basket-type sieves, as apparent in pheromone-sensitive male moths (100), and long internal ducts may create a physical lowpass filter for $\mathrm{CO}_{2}$ detectors that should not be influenced by fast concentration changes (48). Second, sensilla contain several ORNs (from 2 to 200), which together share the same sensillar lymph. A functional role of this colocalization has often been proposed, but no experimental proof exists to date. Conceptually, several modes of interaction are conceivable. For example, the sensillar lymph may create a common 
OBP: olfactory binding protein

OR: odorant receptor

LN: local neuron ion sink, creating an electrochemical coupling of receptor neuron activity. Third, olfactory binding proteins (OBPs) are located in the sensillar lymph and are differentially expressed in different sensilla. Although the role of OBPs is understood only partially, their controlled presence creates selective properties. For example, in D. melanogaster the OBP LUSH is necessary for pheromone detection and selectively expressed in $\sim 150$ trichoid sensilla (118). Fourth, not all receptors are olfactory: hygro-, thermo-, and mechanoreceptors are often colocalized, and this colocalization may have a direct functional role (e.g., converting a receptor neuron for volatile substances into a contact chemoreceptor, if its activity is gated by a mechanoreceptor).

\section{Peripheral Olfactory Organs}

In insects, ORNs are located on the antennae and send their axons into the ALs. In some groups, notably Diptera, the maxillary palps function as additional olfactory organs. Sensory neurons located on the palps also send their axons into the $A L$, into a group of ventral glomeruli that is contiguous but not separate from the remaining glomeruli (VA7l, VC2, VA4, VM7, VC1, 1) $(14,112)$. However, no palp-specific function has been proposed so far. Unlike olfactory receptors (specialized for airborne stimuli), gustatory chemoreceptors are located in many more positions on and in the insect body and have axons that project to various ganglia in the CNS, thus creating several parallel chemosensory systems. In this review, however, gustatory receptors are not considered.

\section{Olfactory Receptor Types}

Each ORN expresses one or more odorant receptor (OR) genes. In insects, these belong to a large family of G-protein-coupled receptors (GPCRs). Unlike other members of this family, they generally occur as heterodimers (in most cases with a ubiquitous partner, Or83b in D. melanogaster, and a specific partner that confers odor selectivity) and are localized within the membrane, with their $\mathrm{N}$-terminal end facing toward the cytoplasm, i.e., inside-out, unlike canonical GPCRs (6). Whether, or to what extent, their transduction involves a second messenger cascade or is ionotropic is currently an area of active research $(92,115)$. There is at least one other family of receptors expressed in insect receptor neurons. These receptors are related to ionotropic receptors (IRs) and appear as odorant-gated ion channels (7). As all ORs, they have their own ligand spectrum, but whether they form a parallel system in functional terms is currently not known.

\section{Axonal Tracts}

Axons from ORNs coalesce into axonal tracts. In the insect antenna, these axons form two tracts, one dorsal and one ventral, and each tract collects axons from sensilla located on the respective side of the antenna. This segregation is entirely topological and does not appear to have functional relevance, even though there might be a structural bias, because sensilla are not homogeneously distributed along the two antennal halves. However, the lack of functional relevance becomes apparent if one follows the tracts into the brain: Shortly before entering the AL, axons form a dense meshwork in the so-called sorting zone and rearrange into different antennal tracts that innervate the $\mathrm{AL}$ (81). Each AL tract receives input from both antennal tracts. Tracts entering the AL have clear functional relevance and are covered in detail below. The number and arrangement of $\mathrm{AL}$ tracts are diverse across species; in the honey bee (Apis mellifera), there are four tracts (T1-T4, plus T5-T6, which are not olfactory and bypass the $\mathrm{AL}$ ).

\section{Neuronal Networks in the AL}

The $\mathrm{AL}$ is the primary processing center for olfactory information. Here, ORN axons interact with a population of neurons local to the AL (local neurons, $\mathrm{LNs}$ ), and with neurons that exit the AL toward other brain areas (projection neurons, $\mathrm{PNs}$ ). ALs are 
structured in glomeruli, which are roundish substructures that contain most synapses within the AL. Each glomerulus is the recipient of one functionally uniform family of receptor neurons, and in most cases there is a substructure within the glomerulus. In most glomeruli of bees, for example, receptor neuron axons innervate the cortex, and PNs the core of a glomeruIus $(22,74)$. LNs interconnect glomeruli and are diverse in morphology, connectivity, and pharmacology. Some LNs have sodium spikes; others have calcium spikes only or are electrotonic (39). Many LNs are inhibitory (express GABA); some are excitatory (are cholinergic). Other transmitters are also used, such as histamine, which is present in $A$. mellifera, in which it functions as an inhibitory transmitter (89), but not in D. melanogaster (71). Subpopulations of LNs also express neuropeptides such as allatostatin (72). In D. melanogaster several GABAergic LN subgroups can be identified with enhancer trap lines, showing that they are molecularly distinct (98). The morphology of LNs differs in terms of their glomerular connectivity (some LNs branch in all glomeruli, some in a subpopulation of glomeruli), polarity (some LNs may receive input in some glomeruli and form output in others, although the inputoutput properties of $\mathrm{LNs}$ have not been studied to date), and intraglomerular arborization (innervating the cortex, the core, or both). A direct involvement of LNs into functional (parallel) subgroups has not yet been shown.

\section{Projection Neurons}

PNs relay olfactory information from the AL to higher-order brain centers. Most PNs are uniglomerular (uPN), which means that within the AL they branch in one glomerulus only, and then send an axon to the MBs, the lateral protocerebrum, or both. uPNs form distinct tracts (see Figure 2), the most prominent of which travels along the brain midline. Tract nomenclature differs among species, but in this review we use APT for all tracts across species (antenno-protocerebral tract, $\mathrm{m}-\mathrm{APT}$ and I-APT for medial and lateral APT, respectively, and $\mathrm{ml}$-APT for mediolateral tract). The different output tracts are discussed in detail below. Whereas some PNs are likely to be cholinergic (e.g., the m-APT PNs in honey bees), the transmitter of others has not yet been identified (e.g., the l-APT PNs in honey bees). In addition to uPNs, there are multiglomerular PNs (mPNs). These branch in several if not all glomeruli and thus are potentially capable of extracting combinatorial activity information. Some but probably not all mPNs are GABAergic, and in general they travel in tracts that are distinct from those used by uPNs. In locusts, all known PNs are mPNs.

\section{Feedback Neurons}

Several feedback and modulatory systems participate in olfactory coding. Modulatory neurons generally use biogenic amines (octopamine, dopamine, and serotonin) as transmitters and/or neuropeptides. A group of ventral unpaired median (VUM) neurons, with a soma located in the subesophageal ganglion, project into the antennae and release dopamine or octopamine, with the effect to increase or decrease receptor neuron sensitivity. In the AL, several neurons that branch in large brain areas innervate olfactory glomeruli and release octopamine, serotonin, dopamine, or peptides. The precise arborization (and even their presence) is diverse across insect groups. Also, in some groups these neurons compartmentalize the AL. For example, in some species of ants the serotonergic neuron innervates only about half the AL, suggesting a different function for this $\mathrm{AL}$ part $(15,120)$. In addition to these large modulatory neurons, there are feedback neurons that innervate the $\mathrm{AL}$ coming from the $\mathrm{MB}$ output lobes, such as the honey bee AL1 (or ALF1) neuron $(47,87)$, potentially creating a direct feedback loop in olfactory processing.

\section{Mushroom Bodies}

PNs in most insect species investigated so far innervate the MB-calyces, where they form distinct synapses with $M B$ intrinsic neurons, the
uPN: uniglomerular projection neuron mPN: multiglomerular projection neuron 


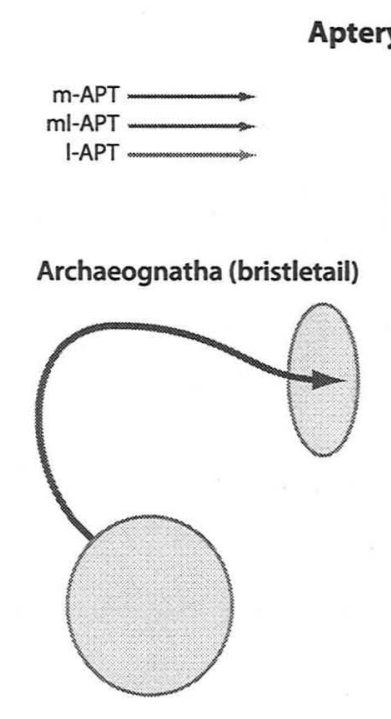

Apterygota

Polyneoptera
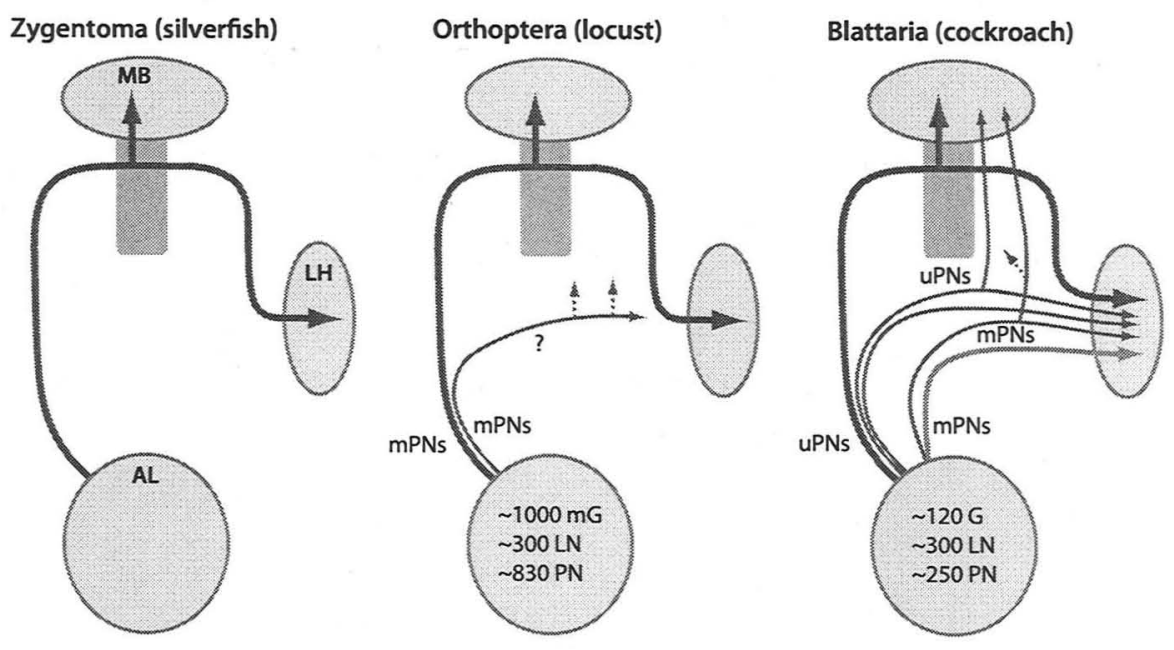

Holometabola
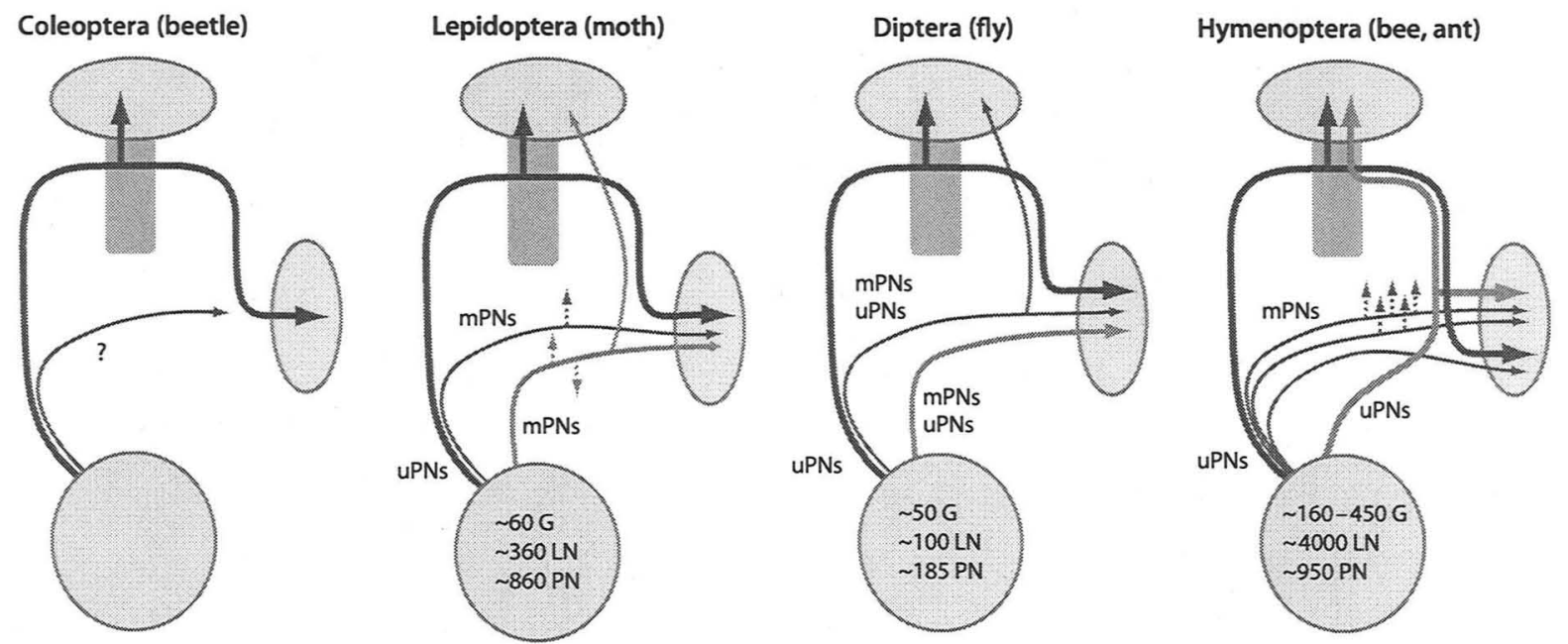

Figure 2

Comparison of olfactory tracts in insects. Schematic comparison of multiple parallel projection neuron (PN) pathways connecting the antennal lobe (AL) with secondary, higher olfactory neuropils in the protocerebrum, the mushroom bodies (MBs), and the lateral horn $(\mathrm{LH})$. Whenever known, the approximate range of the numbers of olfactory glomeruli ( $\mathrm{G}$, glomeruli; $\mathrm{mG}$, microglomeruli, small glomerulus-like structures in the case of the locust $\mathrm{AL}$ ), local interneurons ( $\mathrm{LN}$ ), and uni- and multiglomerular projection neurons $(\mathrm{uPN}, \mathrm{mPN})$ are indicated in the $\mathrm{AL}$. The information was compiled from various published sources: Archaeognatha and Zygentoma $(104,105)$, Orthoptera $(4,40,58)$, Blattaria $(62,105)$, Coleoptera $(17,105,114)$, Lepidoptera $(37,43,79,95)$, Diptera $(41,101,102$, 111), Hymenoptera $(1,22,47,68,69,119,120)$. As the traditional tract nomenclature used for different insect species is rather diverse (i, inner; m, medial; ml, mediolateral; o, outer; 1-ACT, lateral antennocerebral tract), we included a suggestion for a unified nomenclature based on tract position (color-coded for all cases indicated in the upper left; $\mathrm{m}$-, $\mathrm{ml}-$, and l-APT refer to medial, mediolateral, and lateral antenno-protocerebral tract, respectively). 
Kenyon cells (KCs). These form the MB lobes, where they create distinct layers. These layers show characteristic expression patterns for transmitters and neuropeptides, suggesting a subdivision that may be functional and that may also be part of segregated and/or parallel olfactory systems (106). In this review, we do not go into the details of this higher-level segregation.

\section{PHEROMONE-SPECIFIC PATHWAYS IN MOTHS AND OTHER INSECTS}

\section{MGC and Sex-Specific Systems}

ORNs in male moths can be grouped into neurons that respond selectively to the female's sex pheromone (housed in male-specific trichoid sensilla) and those that respond to general odors such as plant compounds (12). Sex pheromone and nonpheromone sensory inputs segregate in the moth AL. Axons of pheromone-sensitive ORNs project into a sexually dimorphic group of enlarged glomeruli, called the macroglomerular complex (MGC), and the remaining ORN axons project to a spatially segregated array of ordinary glomeruli $(30,34,35)$. The presence of the MGC is usually restricted to males. In Manduca sexta, males possess a higher number of uPNs compared with females within a particular cell group of the AL-containing uPNs only, the medial cluster of AL neurons $(37,82)$. Transsexual transplantation experiments in $M$. sexta, in which the antennal imaginal disk was transplanted from a male larva into a female larva, show that MGC glomeruli are induced by ingrowth of sex pheromone-specific ORN axons (82-84).

\section{Is Coding Different in the MGC?}

One interesting question is whether the two subsystems, the MGC glomeruli and the set of ordinary glomeruli, are functionally separated and whether a different strategy is used to encode pheromonal and general odors. Calcium imaging in Heliothis virescens confirms that sex pheromone responses are restricted to the male-specific MGC, and plant odors to ordinary glomeruli (24). In both subsystems, odor information is encoded by combinatorial activation of glomeruli. Electrophysiological studies indicate similar coding strategies in the two systems (12). Serotonergic innervation, in principle, is also similar between the MGC and ordinary glomeruli $(26,45,52)$. However, further investigation of olfactory coding is needed, in particular of small-scale temporal properties, of inhibitory interactions via LNs, and of synchronization and oscillation of PN activities (12). Another question is whether the two subsystems interact with each other, i.e., how segregated are these parallel systems, really? Responses of pheromone-specific ORNs may be modulated by certain host plant volatiles, indicating interactions among the two subsystems at the very periphery (73). The interaction between the two systems may be one of mutual exclusion. Behaviorally, mating and host finding occur at different times in most species, suggesting that mechanisms that would increase sensitivity in one system at the expense of the other would increase the efficiency of olfactory processing. On the other hand, in some species females sit on their preferred food plant when calling, indicating that pheromone odor in the context of host odor might be more effective. The findings of combinatorial coding within the two subsystems, and of interactions among them, expand the previously proposed more or less strict segregation of two separate subsystems in the moth, a pheromone-specific labeled-line system and a combinatorial system for general odors (12).

\section{Sex Pheromone Systems in other Species}

Sex-pheromone-specific MGCs are found in males of many species, including honey bees, ants, and cockroaches $(5,8,38,91,113)$. MGCs in these species may be located in different areas of the AL, or even distributed across it, instead of at the AL entrance, as in moths. But not all species have an MGC: Males of the carpenter ant Camponotus floridanus do not possess
KC: Kenyon cell 
Lateral horn $(\mathrm{LH})$ neuropil area in the lateral protocerebrum that receives input mainly from olfactory PNs (uPNs and $\mathrm{mPNs}$ ) an enlarged sex-specific glomerulus, indicating that sex pheromones are processed in normally sized glomeruli (120). Sexual dimorphism in Hymenoptera is covered below. The sexual dimorphism of $D$. melanogaster pheromone glomeruli is also limited.

\section{Nonsexual Pheromone Systems}

In addition to sexual pheromones, many insects-notably but not only social insectsuse chemical cues for communication and therefore need an olfactory system to process nonsexual pheromone information. So far, a specialized anatomical substructure for nonsexual pheromones has been shown only in the leafcutter ants. Sterile workers of leafcutter ants (Atta vollenweideri, Atta sexdens) possess a substantially enlarged macroglomerulus at the entrance of the $\mathrm{AL}$ that processes information about the species-specific trail pheromone $(49,51)$. Leafcutter ants are highly polymorphic, and only the large workers possess a macroglomerulus-it is absent in small workers, which preferentially stay inside the nest. On the other hand, the $\mathrm{AL}$ of C. floridanus does not contain a substantially enlarged macroglomerulus, but a distinct group of normally sized glomeruli responds to the major component of the species-specific trail pheromone (nerolic acid) (119). The glomerular activation in response to nerolic acid is highly sensitive and concentration invariant over a wide range of concentrations ( $\sim 6 \log$ units). No similar specialization has yet been found in other species. For example, female worker honey bees produce and respond to alarm pheromone, queen pheromone, and Nasonov gland pheromone, but they do not possess an enlarged glomerulus or MGC (22, 47). They process these pheromones by combinatorial patterns of glomerular activation (23).

\section{Are Pheromone Systems Plastic?}

Pheromones constitute innate signals, reducing the importance of plasticity in the system. Therefore, one hypothesis about these parallel systems could be that pheromone systems lack the plasticity shown by the remaining olfactory system. However, sex pheromone processing is not entirely hardwired. Behaviorally, sex pheromone sensitivity depends on sexual maturity and mating status. Premating and postmating plasticity of pheromone processing are regulated by juvenile hormone in Agrotis moths (3, 16, 20). Juvenile hormone controls glomerular plasticity in honey bees: Associated with the lifestyle switch from nurse to forager, some glomeruli change their overall size $(11,96,117)$. Somewhat counterintuitively, moths can be trained to associate a sugarwater (i.e., appetitive) reward with a pheromone stimulus (32). Similar effects were shown for the general odor system, suggesting that both odor coding and plasticity mechanisms are not much different between pheromone and nonpheromone systems (12).

\section{Open Questions about Pheromone Coding}

There are still many open questions about the segregation of pheromone processing and coding of general odors, both at the level of the AL (as discussed in this review) and in particular at the higher levels in the $M B$ and lateral horn (LH) (which is not covered here). For example, is information from general odors and from pheromonal odors spatially and functionally segregated in higher centers, as it is the case in D. melanogaster? Do ecological constraints influence functional and spatial segregation of pheromonal and nonpheromonal information processing? Is temporal processing and neuromodulatory control different in both subsystems? It seems that both pheromonal and nonpheromonal systems house PNs with different temporal response properties and dynamic ranges, which would argue against fundamental differences (12). How is the information from both subsystems transferred via parallel pathways? In the cockroach, for example, MGC information from uPNs was relayed solely via the i-ACT (equivalent to m-APT in the nomenclature of this paper) (Figure 2) (62), whereas in 
D. melanogaster two tracts are used. The situation in other systems is less well known and requires further investigation.

\section{PARALLEL OLFACTORY PATHWAYS IN DROSOPHILA}

In $D$. melanogaster, a clear distinction between the pheromone system and the remainder of the olfactory system is apparent. In addition, there is a separation of functional properties at the level of sensory neurons that in part transmits through several processing areas.

\section{The Drosophila Pheromone System}

Several $D$. melanogaster receptor neurons are involved in pheromone detection. Unlike the situation in moths, fruit flies use pheromones for short-range interaction. Cuticular hydrocarbons are detected by males and by females in immediate vicinity to the mating partner, and they play a role together with a complex behavioral protocol consisting of tapping, singing, and dancing. Finally, when all signals are right, mating occurs, and the male also deposits a deterrent pheromone into the female's vagina (56). The mated female therefore produces a different odor than virgin females do, resulting in a repellent action toward other males. Both sexes smell these sexual pheromones, but their behavioral relevance is different.

The strongest molecular distinction is given by the fruitless gene, which is expressed in a male-specific form in several neurons throughout the brain and notably also in a subpopulation of receptor neurons that innervate trichoid sensilla $(63,103)$. It has been proposed that trichoid sensilla are generally related to pheromone reception in $D$. melanogaster (112), which would represent a correlation between sensillum morphology and functional specialization. fruitless controls most male sexual behavior, and its male-specific splicing is controlled by another gene, transformer (33). As a result of these genes, the glomeruli DAl (innervated by Or67d) and VAlml (innervated by
Or47b) are larger in males than in females, whereas VL2A, which is also innervated by fruitless-controlled neurons, does not show sexual dimorphism (53). Among the odors that act as pheromones, $D$. melanogaster uses cisvaccenyl acetate $(2,13)$. Cis-vaccenyl acetate is coded by the receptor Or67d (glomerulus DA1) and does not need a combinatorial analysis in the brain. Activity in Or67d acts as a repellent toward other males and as an attractant for females (56). Other cuticular hydrocarbons remain to be identified.

Functionally, pheromones use a system parallel to the remaining olfactory pathway in D. melanogaster. How distinct is this pathway in morphological and structural terms? Do projections from pheromone-sensitive glomeruli and the remaining glomeruli project to different areas of the brain? Yes, indeed they do. The target areas of pheromone-sensitive PNs are clustered in the anterior-ventral area of the LH, whereas fruit-odor-sensitive PNs project to the posterior-dorsal LH (42). Two distinct groups of uPNs leave the pheromoneselective glomeruli VA1Im and DA1 toward the LH: One group is cholinergic and excitatory and sends the axons via the $\mathrm{i}-\mathrm{ACT}$ (m-APT in our nomenclature, see Figure 2), whereas the other group is GABAergic and inhibitory and sends the axons via the m-ACT (ml-APT in our nomenclature) (42). In the LH the two axons target the same area, allowing neurons here to potentially read out all possible relative combinations of VA1Im and DA1 glomeruli activity; in particular it is possible to extract mixture ratios of pheromone components. Thus, functionally, the situation is similar to that for ratio-selective interaction within the pheromone system in moths. To our present knowledge, this situation is unique to this subsystem. In all other glomeruli, uPNs are excitatory and send their axons via the m-APT to $\mathrm{MBs}$ and $\mathrm{LH}$, whereas inhibitory $\mathrm{PNs}$ are multiglomerular. Thus, pheromones and nonpheromones represent parallel processing systems in D. melanogaster that also follow different processing steps and decoding algorithms. 
ORs and IRs: Parallel Receptor Systems?

D. melanogaster has two distinct populations of ORNs: one that expresses conventional ORs, which are related to the GPCR family, and one that expresses IRs, which are related to ionotropic channels (7). Response profiles in conventional ORs cover fruit odors and pheromones. For the IR family, of which members are expressed in coeloconic sensilla, few ligands have been identified, including putrescine, ammonia, and water vapor. Axons from coeloconic sensilla project to a group of ventrally located glomeruli, including DC4, VM1, VM6, DL2, and VL2. Little is known about how IR-expressing ORNs interact in their further processing with the remainder of the olfactory system. Do they form a parallel olfactory system? Which of the two systems arose earlier in evolution, and what is their functional relevance? These questions remain to be elucidated.

\section{The $\mathrm{CO}_{2}$ System: Labeled Lines}

D. melanogaster also gives us an example for a single-glomerulus labeled line system that acts in parallel to the remaining olfactory system (see also Figure 4a). $\mathrm{CO}_{2}$-selective ORNs are highly specific for this substance: They express Gr21a and Gr63a, a receptor pair that is structurally related more closely to the gustatory receptors than to the other olfactory receptors. The axons innervate glomerulus V. Removing the receptors makes flies anosmic to $\mathrm{CO}_{2}$ and ablates behavioral responses to $\mathrm{CO}_{2}$ (107). Thus, this glomerulus alone is necessary and sufficient for $\mathrm{CO}_{2}$ perception, in parallel to the general olfactory system conveyed by the remaining glomeruli. Nevertheless, $\mathrm{LNs}$ within the AL innervate the $\mathrm{V}$ glomerulus (90), suggesting that even in this apparently clearcut segregate parallel system there is communication with the remaining olfactory compartments: Parallel systems are not isolated systems, and their activity is also integrated within the brain networks, already at the level of the $\mathrm{AL}$.

\section{OLFACTORY OUTPUT TRACTS ACROSS INSECTS}

The PN connections between the $\mathrm{AL}$ and higher olfactory centers in the brain have been investigated in various insect species, and multiple $\mathrm{AL}$ output tracts are present in many insects studied so far. The comparison of anatomical specializations of the AL output tracts across insects at different organizational levels can be elusive for our understanding of general principles in olfactory processing along parallel pathways. The traditional nomenclature of the antennocerebral tracts used in the literature differs among insect species. In some species, $\mathrm{m}, \mathrm{ml}$, and $\mathrm{l}$ represent medial, mediolateral, and lateral. In other species $\mathrm{i}, \mathrm{m}$, and o represent inner, middle, and outer. To ease comparative analyses, we use in this paper a new nomenclature: APT for the tracts, and m-, $\mathrm{ml}-$, and I-APT for medial, mediolateral, and lateral antenno-protocerebral tract, respectively. As the new nomenclature is purely based on position (innermost, intermediate, and outermost tract positions), the tract names (e.g., m-APT or 1-APT) do not necessarily imply homology.

The only cases with a single connection between the AL and higher olfactory centers in the protocerebrum via the m-APT are found in the basal Apterygota, the Archaeognatha (bristletails; Malacbis germanica), in which no MBs are present, and in Zygentoma (silverfish) (Figure 2) (104, 105). In the locust (Orthoptera), the situation is more or less similar to that in the Zygentoma-but the situation in the locust (Orthoptera) is special because all PNs are mPNs, and they form a single prominent $\mathrm{m}$-APT pathway to the MB and LH with only some diffuse connections to the lateral protocerebrum (see caption to Figure 2 for a list of references). The complexity found in Blattaria (cockroach) is much higher, with a full complement of m-APTs, several ml-APTs with connections to the MB and LH, and an I-APT that ends in the LH. Within the Holometabola, the Coleoptera appear to represent a more basal organization, with only one prominent APT 
connecting the $\mathrm{AL}$ to the $\mathrm{MB}$ and $\mathrm{LH}$. The comparison across different insect orders suggests that the presence of parallel olfactory pathways in higher-order brain centers is a common trait in many insect olfactory systems, with the highest level of complexity in the Blattaria, Diptera, and Hymenoptera $(47,119)$. The ml-APTs are subdivided into subtracts (II, III, IV in the cockroach, and 1, 2, 3 in the honey bee and fly). Hymenoptera have a prominent 1-APT formed by uPNs that connect the AL to the $\mathrm{LH}$ and $\mathrm{MB}$, the order of which is reversed for m-APT. Unfortunately, only a few hemimetabolous species have been investigated so far with respect to this trait. It would be interesting to study termites (Isoptera) in the future: Could an increase in the complexity of parallel olfactory pathways be associated with the social lifestyle?

\section{DUAL OLFACTORY PATHWAY IN HYMENOPTERA}

\section{Structural Subdivision of Input and Output Tracts}

In Hymenoptera, input and output streams of the AL are subdivided structurally and have been well investigated. In the honey bee, distinct clusters of olfactory glomeruli in the $\mathrm{AL}$ are innervated by four antennal sensory input tracts (T1-4) (Figure 3) $(19,47,68,74,108)$. Sensory input tracts are connected to multiple PN output tracts, the AP'Ts (called ACTs in most honey bee papers), that project to higherorder brain areas: the lateral 1-APT, the medial $\mathrm{m}$-APT, and three mediolateral ml-APTs $(1,44$, 47). Whereas $\mathrm{m}$-APT and I-APT are formed mainly by uPNs innervating single glomeruli, $\mathrm{ml-APTs}$ are formed by mPNs with dendritic arborizations in many glomeruli.

The organization is similar in C. floridanus despite a substantially higher number of sensory input tracts ( $\mathrm{T} 1-7$; compared with $\mathrm{T} 1-4$ in $A$. mellifera) and almost three times as many olfactory glomeruli (434 compared with 163 in A. mellifera) $(119,120)$. Both bees and ants show a striking similarity in that their $A L$ is subdivided into two hemilobes that contain an almost equal number of glomeruli feeding uPNs into the l-APT and m-APT output tracts. Furthermore, the axonal target fields of the two uPN pathways remain spatially segregated in the higher centers in the MB and LH: Axonal projections of $\mathrm{m}$ - and 1-APT neurons occupy different domains in the lip and basal ring of the MB-calyx and within the LH (Figure 3) $(47,119)$.

The obvious spatial segregation of the $\mathrm{m}$ and $\mathrm{l}-\mathrm{APT}$ projections in the MB-calyx and $\mathrm{LH}$ indicates that the two sensory input streams are differentially processed in the higher olfactory centers. Depending on their dendritic input fields, different classes of KCs may pick up information from only one or from both input streams. Additional physiological studies (optical imaging and electrophysiological recordings) are necessary to further understand this aspect.

Studies on the two major AL output pathways in the honey bee indicate that the two classes of uPNs, m- and 1-ACT uPNs, differ in physiological properties $(1,69)$, suggesting that they might mediate different properties for odor perception. For example, one system might filter odor quality information, and the other the time-structure of a stimulus and its concentration; or one might process blend information (synthetic coding), while the other could extract odor mixture components (analytical coding). This arrangement would be reminiscent of parallel streams in the visual systems of many species. The two systems may accomplish different tasks for olfactory learning and memory, one coding odor quality in an experience-dependent way and the other in an experience-independent way (76). In addition, the relevance of temporal parameters, such as synchronizations and oscillations of $\mathrm{PN}$ populations (57), and their connection via the two $\mathrm{PN}$ pathways to the MB are unclear. To understand fundamental principles of olfactory processing and perception, we still need to unravel the mechanisms underlying different properties of PN output streams and their functional consequences. 


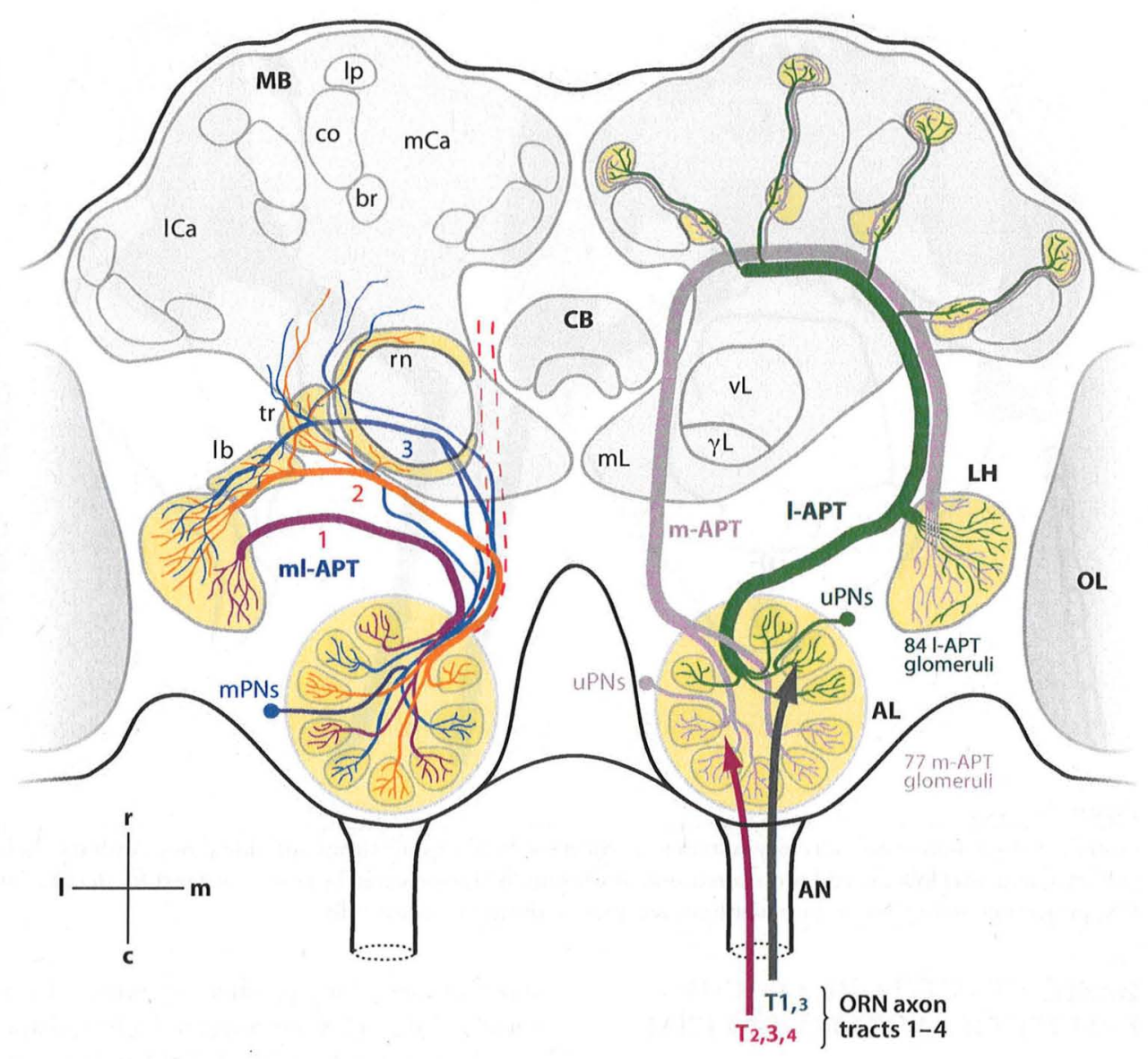

Figure 3

Parallel systems in the honey bee. Schematic overview of the dual olfactory system in honey bees. Four antennal nerve (AN) sensory input tracts (T1-4) (Note that font size is indicative of the difference in tract size) innervate the olfactory glomeruli in the antennal lobe (AL), as indicated on the lower right side. The left side of the schematic brain shows the projections of multiglomerular projection neurons ( $\mathrm{mPNs}$ ) along three mediolateral antenno-protocerebral tracts (ml-APT 1-3), which innervate many glomeruli across the AL. Their target areas are the lateral horn (LH) and a lateral network in the lateral protocerebral lobe with the ring neuropil ( $\mathrm{rn})$, triangle (tr), and lateral bridge (lb). The right side shows medial (m-) and lateral (l-)APTs, which comprise uniglomerular projection neurons (uPNs) receiving input from individual glomeruli in two hemilobes of the AL. The uPN axons from both tracts target specific regions in the basal ring (br) and lip (lp) of the mushroom body (MB)-calyces and separate domains in the LH. Further abbreviations: $\mathrm{CB}$, central body; c, caudal; co, collar; l, lateral; m, medial; $\mathrm{mL}$, medial lobe; $\mathrm{ORN}$, olfactory receptor neuron; r, rostral; vL, vertical lobe; $\gamma \mathrm{L}$, gamma lobe. Modified and adapted with permission from Reference 47.

\section{APT Neurochemistry}

The neurochemistry of PNs supplying the different APTs further indicates functional diversity among the pathways. Many aspects of the neurochemistry are still unclear, but there appears to be at least some diversity among the
APTs. Histochemical stainings against acetylcholinesterase in the honey bee suggest that acetylcholine functions as a neurotransmitter in the m-APT, but not in the other APTs including the prominent l-APT (54). There is strong taurine-like immunoreactivity in 1-APT (94), with somata of taurine-positive neurons located 
in specific areas, and taurine-like immunoreactivity concentrated in the posterior glomeruli. However, evidence is not yet sufficient to attribute taurine or any other transmitter to the 1-APT tract.

Several neurotransmitters and neuromodulators are heterogeneously distributed in the $\mathrm{AL}$ across and within Hymenoptera. Dopaminergic neurons, for example, are absent in the $\mathrm{AL}$ of the ponerine ant Harpegrathos saltator (38) but show an approximately homogeneous distribution in the honey bee AL (46). Serotonergic neurons innervate most if not all AL glomeruli in many species, including $A$. mellifera, $H$. saltator, and a wide range of nonhymenopteran insects, suggesting a high degree of phylogenetic conservation $(15,38,45,77)$. In carpenter ants, however, a large proportion of glomeruli in the posterior part of the AL is devoid of serotonergic innervations. These glomeruli feed into the $\mathrm{m}-\mathrm{APT}$, suggesting that $\mathrm{l}$ - and $\mathrm{m}-\mathrm{APT}$ pathways are differentially modulated at the level of the AL in this species $(15,120)$. GABAergic staining is found in many LNs, with a fairly uniform distribution across glomeruli. In bees, a small population of GABAergic neurons forms a connection between the two ALs (93). The function and exact position of glomeruli innervated by these bridge neurons are still unclear (e.g., whether they encompass all glomeruli or only a subpopulation, and whether they belong to $\mathrm{m}$ - or 1-APT glomeruli). Similarly, histaminergic local neurons were found across many AL glomeruli spanning across both hemilobes (9). Whether other neurotransmitter/modulator systems, diffusible messengers such as nitric oxide, or neuropeptidergic neurons display sensory-tract, hemilobe-, or output-tract-specific differences remains to be investigated in the future.

\section{Sexual Dimorphism in Hymenoptera}

In Hymenoptera, males generally have fewer glomeruli than females do. For example, the total number of glomeruli in honey bee drones is lower compared with the conditions in the female castes $(\sim 106$ glomeruli in drones, compared with $\sim 164$ glomeruli in workers and in queens) $(5,27,91)$. In $H$. saltator, males have $\sim 78$ glomeruli, whereas females have $\sim 176$ glomeruli (38). In C. floridanus, males have $\sim 258$ glomeruli and females have $\sim 434$ glomeruli-a reduction by $\sim 40 \%(119,120)$. Most importantly, in C. floridanus the reduction of glomeruli is nearly restricted to glomeruli associated with the $\mathrm{m}-\mathrm{APT}$, in particular within glomeruli innervated by sensory tracts 5 and 6 . In contrast, the number and organization of I-APT-associated glomeruli are not sexually dimorphic in this species. Thus, the $1-\mathrm{APT} / \mathrm{m}$ APT dual pathway appears to have a sex-specific connotation in C. floridanus $(119,120)$ and may therefore have the connotation of a segregated parallel system. In addition, unlike in other Hymenoptera, serotonergic innervation of the $\mathrm{m}$ - and I-APT hemilobes differs across sexes. Whereas most of the m-APT glomeruli lack serotonergic innervations in the female $\mathrm{AL}$, all $\mathrm{AL}$ glomeruli in males are innervated by serotonergic processes, including those in the $\mathrm{m}$-APT part of the AL (120). These findings indicate fundamental differences in glomerular composition and neuromodulatory control of the m-APT hemilobe between both sexes. Thus, functional differences between parallel systems may be related to sex-specific tasks or to differences in odor coding for sex-specific stimuli. Because males in social Hymenoptera usually do not engage in social tasks (36), these differences may also be related to the different needs in the reception and processing of social odors.

\section{STRUCTURE AND FUNCTION OF PARALLEL OLFACTORY PATHWAYS}

In this review, we have highlighted several cases in which olfactory information is processed in parallel streams. Figure 4 summarizes and extends this overview, proposing five cases that are not always mutually exclusive and that contain highly putative elements. 


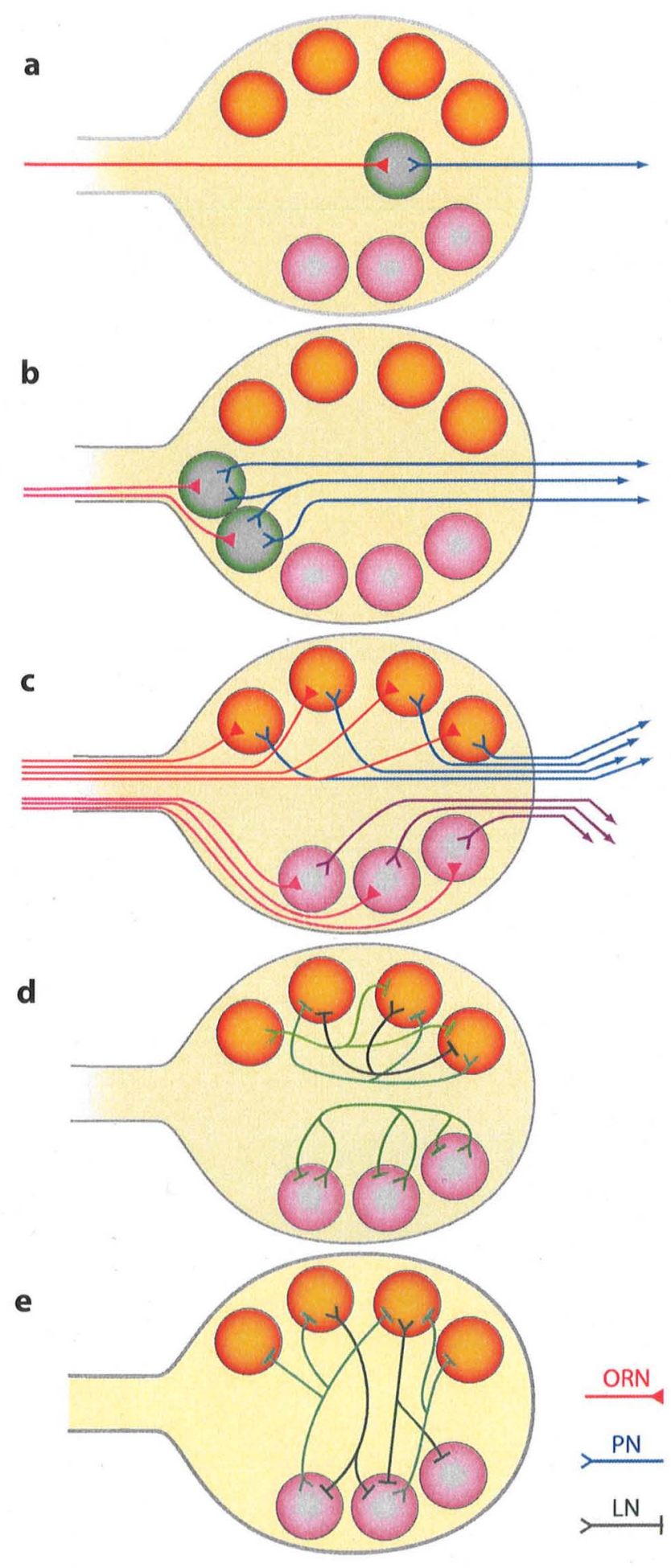

The Labeled Line System (Segregated)

In a true labeled line system, a population of ORNs innervates a single glomerulus, and uPNs from this glomerulus relay that information to higher-order brain centers (Figure $4 a$ ). The presence, identity, and concentration of a stimulus are entirely decodable from the activity in this single channel. So far, the best known system of this kind is the $\mathrm{CO}_{2}$ system in D. melanogaster and in $M$. sexta. $\mathrm{CO}_{2}$ selective perception is also present in other insects (99), but whether the segregation from the remaining olfactory system is as strong is unknown. As stated above, the labeled line $\mathrm{CO}_{2}$ glomerulus, however, is not isolated from the remaining olfactory network, but rather interconnected via LNs.

Species differ in their functional requirements for $\mathrm{CO}_{2}$ perception. Flies have phasictonic $\mathrm{CO}_{2}$ responses, whereas bees and ants sense $\mathrm{CO}_{2}$ for ambient air control in their hives and therefore need a receptor with tonic response properties. Indeed, in ants, $\mathrm{CO}_{2}$ receptors are located deep within sensilla that act as a physical low-pass filter, further adding to their tonic response properties (48). The $\mathrm{CO}_{2}$ receptor found in D. melanogaster (Gr21a and Gr63a) has a homolog in mosquitoes but not in bees (80): It is possible that it was easier to evolve a

\section{Figure 4}

Different parallel system scenarios. Different nonexclusive cases for parallel systems are shown schematically. The AL is shown in yellow, two distinct groups of glomeruli are shown as pink and orange circles, specialized glomeruli are green circles. See text for a detailed discussion. (a) A true labeled line system (segregated parallel system), e.g., $\mathrm{CO}_{2}$ detection in flies. (b) A combinatorial labeled line system (segregated parallel system), e.g., sex pheromones in moths. (c) A duplicated (multiplied) system, e.g., the 1-APT and m-APT system in bees. (d) A separate processing system, e.g., a possible hypothesis for coding differences in parallel systems. (e) An interactive separate processing system, e.g., another hypothesis for dual parallel systems. Abbreviations: $\mathrm{LN}$, local neuron; ORN, olfactory receptor neuron; PN, projection neuron. 
new receptor than to change a phasic receptor into a tonic receptor, or vice versa. What at first appeared to be a parallel processing system in mosquitoes $\left(\mathrm{CO}_{2}\right.$ detection via the maxillary palps) and for other odors (host finding, adult flower feeding, and oviposition site selection, all via the antennae), now appears to be more complicated, with the maxillary palps detecting several odorants of behavioral significance $(109,110)$.

In $M$. sexta, $\mathrm{CO}_{2}$ information is also processed at the level of the AL. Functional requirements are likely different in this species as well: $\mathrm{CO}_{2}$ is part of the floral display and thus used for food location, suggesting at least some degree of interaction with other odor stimuli (28). Interactions may even extend to other modalities that are processed at the level of the AL. For example, both temperature and relative humidity affect the responses of male moths to sex pheromones $(85,86)$. Whether, and to what extent, temperature and humidity processing are integrated into the olfactory system and/or form parallel processing streams still needs to be established.

\section{The Combinatorial Labeled Line System (Segregated)}

The classical example of a labeled line system is the sexual pheromone system in moths (Figure 4b). Anatomical and functional segregation of the MGC from the remaining AL in male moths is a clear example of parallel olfactory systems, although as in the $\mathrm{CO}_{2}$ case the isolation is not complete because LNs may interconnect the pheromone and general odor systems. Importantly, odor coding within the MGC is not labeled line, but combinatorial: Most sexual pheromones consist of several active substances at a speciesspecific concentration ratio. Thus, uPNs can code for the presence of a pheromone component, but $\mathrm{mPNs}$ (Figure $4 b$ ) may be blend specific (31). Whether this is accomplished by PNs branching directly into multiple glomeruli, as schematically suggested in the figure, or indirectly via $L N$ connectivity is not known. As presented above, sexual dimorphism in insects other than moths has also been shown, but the separation appears to be less strict.

\section{The Duplicated (Multiplied) System}

In this parallel system, different populations of ORNs innervate specific groups of glomeruli, and $\mathrm{uPNs}$ leave the $\mathrm{AL}$ via distinct tracts (Figure 4c), as is the case for honey bees and other Hymenoptera (Figure 3). Possible functional implications are discussed above. Two of these relate to the local networks within the $\mathrm{AL}$ and are shown in Figure 4d,e.

In these systems, a clear separation is apparent morphologically, but it needs more work to be understood functionally, particularly whether they form segregated or interacting parallel pathways. Conceptionally, the whole range of parallel systems may be realized in this architecture: from the segregated system, in which each stream is devoted to its own class of odors, but coding logic might even be identical, to the true parallel system, in which identical stimuli are processed but different information is extracted. Furthermore, "dual" does not imply that parallel systems be limited to twomultiple parallel systems are likely to consist of more than two streams. Connectivities as shown in Figure $4 e$ propose cases in which parallel streams are far from independent.

\section{The Separate Processing System (Dual)}

In a dual processing system, each group of glomeruli may be interconnected by a specialized network of LNs that processes information geared toward different properties in the stimulus. Figure $4 d$ shows a complex, glomerulusspecific network that interconnects the upper glomeruli. Such a network, which has been shown in honey bees (59) and in flies (97), might be relevant for decorrelating glomerular information streams. Such a network extracts odor-quality information. The lower glomeruli 
are interconnected by a network of homogeneous LNs that have input and output in all glomeruli and that may work as a global gain-control mechanism, increasing sensitivity at low concentrations and avoiding saturation at high concentration. How LN networks may filter different odor information depending on their connectivity has been discussed elsewhere $(25,88)$. Although such networks have been shown in several species, segregation of these two connectivity types into distinct groups of glomeruli is currently a hypothesis for which there is no experimental evidence.

\section{The Interactive Separation (Dual)}

Another hypothetical function is shown in Figure $4 e$. Here, the two glomerular subsystems are interconnected rather than completely separated. Such connectivity would create a reverberating network that could be used for the generation of oscillations and/or for temporally segregated information coding (i.e., the upper glomerular group would fire when the lower one is silent, and vice versa). In such a network the two subsystems would probably code for the same odors, as shown by physiological recordings in honey bees $(55,69)$. A similar system has been proposed for the mammalian olfactory bulb, which is split into two distinct hemilobes consisting of glomeruli innervated by the same receptor neuron populations and interconnected by inhibitory neurons (61). No explicit evidence for this arrangement has yet been found in insects.

\section{Target Area Functions}

All scenarios shown in Figure 4 involve AL networks. Downstream areas are just as likely to be involved in parallel processing. For example, the dual arrangement shown in Figure $4 c$ may be related to a readout system in the $M B$, whereby the two distinct APTs form different delay lines to the MB and LH. Thus, KCs in the MBs may be able to extract synchronous spikes depending on their exact location within the lateral and medial $\mathrm{MB}$-calyces (see above and compare with Figure 3).

\section{CONCLUSION AND SUMMARY}

We have reviewed different types of parallel systems, but they all fall into one of two distinct classes, either segregated or dual. The segregated class is dictated by the stimulus that is being encoded (Figure $4 a-c$ ): sex pheromone versus general odors, or other special stimuli such as $\mathrm{CO}_{2}$ or humidity, among others. In this class, processing can remain largely segregated between the systems, although interactions occur, and coding strategies within the systems are often similar (e.g., the combinatorial system). The dual class is not dictated by the stimulus quality, but rather by the logic of odor processing (Figure $4 c-e$, with Figure $4 c$ falling into both classes).

The organization into two parallel processing streams allows for separate extraction of stimulus properties (such as odor quality and odor concentration, or blend information versus analytical analysis of mixture components) or for parallel odor-processing steps that are incompatible (e.g., one system for phasic coding of fast odor fluctuations, and another system for tonic coding of slow odor changes; part of this may already be present at the level of ORNs). A third functionally dictated parallel organization is more cooperative: It allows for the creation of either reverberating networks (Figure $4 e$ ) or delay lines with opposing polarity, which would allow recipient cells to extract subtle spike-timing differences along delay lines.

As presented in this review, examples abound for stimulus-related (segregated) parallel systems that have been investigated in many species (e.g., pheromones and $\mathrm{CO}_{2}$ ). Functionrelated (dual) parallel olfactory systems are less well understood. In particular, whether these represent different or similar spatial odor maps and whether these perform differential processing have been discussed controversially (55, 69). Alternatively, or in addition, they may perform different computational tasks associated 
with learning and memory (75). These issues are far from being solved and require intensive and combined physiological, neuroanatomical, and behavioral investigations in the future. In insects, the best known system of this kind is realized in the honey bee, with the obvious segregation into 1-APT and m-APT uPNs. A thorough investigation of theseand similar-systems will provide us with an attractive opportunity to understand parallel odor processing at functional and mechanistic levels.

\section{FUTURE ISSUES}

1. More detailed and comparative information on the anatonical projections of different antennal sensilla is needed to understand the basis and logic of glomerular odor maps at the input side. In particular, a molecular understanding in species other than D. melanogaster is needed to map odorant receptor gene to ORN to glomerulus.

2. The link between anatomy and physiology (structure and function) needs to be better understood. In honey bees, for example, careful neurophysiological investigations of the odor maps in the $\mathrm{m}$-APT and 1-APT hemilobes may reveal spatial and temporal coding strategies, and their role in odor coding and memory, both within and across parallel streams

3. A comprehensive understanding of parallel streams requires detaled information about neurotransmitters, neuromodulators, and both structure and function of LNs that may provide distinct computations within and across subsystems. For example, why are most segregated parallel systems still connected, via LNs, to the remaining olfactory streams?

4. The comparative approach is strong and fruitful in insects. Structural, physiological, and behavioral data, within Hymenoptera and across insect orders, are needed for understanding fundamental principles in parallel processing. Particularly interesting is whether the complexity of multiple parallel pathways increases with social lifestyle (e.g., in Isoptera).

5. Behavioral tests in combination with functional manipulations (e.g, ablations or pharmacological treatments) are needed to finally prove the relevance of parallel pathways. In the honey bee, using well-established learning paradigms, this may include cognitionlike processes and complex social behaviors. In the fruit fly, molecular tools can be used to improve mechanistic explanations.

\section{DISCLOSURE STATEMENT}

The authors are not aware of any affiliations, memberships, funding, or financial holdings that might be perceived as affecting the objectivity of this review.

\section{ACKNOWLEDGMENTS}

We thank Nick Strausfeld for his scholarship on comparative aspects of tract morphology across insects, and Christine Dittrich for help with Figures 1 and 4. Funding was provided by DFG SFB 554 (A8) and HFSP to WR, by the German Bundesministerium für Bildung und Forschung (01GQ0771) to CGG, and by DFG SPP1392 to both authors. 


\section{LITERATURE CITED}

1. Abel R, Rybak J, Menzel R. 2001. Structure and response patterns of olfactory interneurons in the honeybee, Apis mellifera. 7. Comp. Neurol. 437:363-83

2. Amrein H. 2004. Pheromone perception and behavior in Drosopbila. Cum: Opin. Neurobiol. 14:435-42

3. Anton S, Gadenne C. 1999. Effect of juvenile hormone on the central nervous processing of sex pheromone in an insect. Proc. Natl. Acad. Sci. USA 96:5764-67

4. Anton S, Ignell R, Hansson BS. 2002. Developmental changes in the structure and function of the central olfactory system in gregarious and solitary desert locusts. Microsc. Res. Tech. 56:281-91

5. Arnold G, Masson C, Budharugsa S. 1985. Comparative study of the antennal lobes and their afferent pathway in the worker bee and the drone (Apis mellifera). Cell Tissue Res. 242:593-605

6. Benton R, Sachse S, Michnick SW, Vosshall LB. 2006. Atypical membrane topology and heteromeric function of Drosophila odorant receptors in vivo. PLoS Biol. 4:e20

7. Benton R, Vannice KS, Gomez-Diaz C, Vosshall LB. 2009. Variant ionotropic glutamate receptors as chemosensory receptors in Drosophila. Cell 136:149-62

8. Boeckh J, Tolbert LP. 1993. Synaptic organization and development of the antennal lobe in insects. Microsc. Res. Tech. 24:260-80

9. Bornhauser BC, Meyer EP. 1997. Histamine-like immunoreactivity in the visual system and brain of an orthopteran and a hymenopteran insect. Cell Tissue Res. 287:211-21

10. Breer H, Fleischer J, Strotmann J. 2006. The sense of smell: multiple olfactory subsystems. Cell Mol. Life Sci. 63:1465-75

11. Brown SM, Napper RM, Thompson CM, Mercer AR. 2002. Stereological analysis reveals striking differences in the structural plasticity of two readily identifiable glomeruli in the antennal lobes of the adult worker honeybee. F. Neurosci. 22:8514-22

12. Christensen TA, Hildebrand JG. 2002. Pheromonal and host-odor processing in the insect antennal lobe: how different? Curr. Opin. Neurobiol. 12:393-99

13. Costa R. 1989. Esterase-6 and the pheromonal effects of cis-vaccenyl acetate in Drosophila melanogaster. 7. Evol. Biol. 2:395-407

14. Couto A, Alenius M, Dickson BJ. 2005. Molecular, anatomical, and functional organization of the Drosophila olfactory system. Curr. Biol. 15:1535-47

15. Dacks AM, Christensen TA, Hildebrand JG. 2006. Phylogeny of a serotonin-immunoreactive neuron in the primary olfactory center of the insect brain. 7. Comp. Neurol. 498:727-46

16. Duportets L, Dufour MC, Couillaud F, Gadenne C. 1998. Biosynthetic activity of corpora allata, growth of sex accessory glands and mating in the male moth Agrotis ipsilon (Hufnagel). 7. Exp. Biol. 201(Pt. 16):2425-32

17. Farris SM. 2008. Tritocerebral tract input to the insect mushroom bodies. Artbropod. Struct. Dev. 37:492503

18. Fishilevich E, Vosshall LB. 2005. Genetic and functional subdivision of the Drosophila antennal lobe. Curr: Biol. 15:1548-53

19. Flanagan D, Mercer AR. 1989. An atlas and 3-D reconstruction of the antennal lobes in the worker honey bee, Apis mellifera L. (Hymenoptera: Apidae). Int. 7. Insect. Morphol. Embryol. 18:145-59

20. Gadenne C, Renou M, Sreng L. 1993. Hormonal-control of pheromone responsiveness in the male black cutworm Agrotis ipsilon. Experientia 49:721-24

21. Galizia CG. 2008. Insect olfaction. In The Senses: A Comprebensive Reference. Vol. 4: Olfaction \& Taste, ed. S Firestein, GK Beauchamp, pp. 725-70. San Diego: Academic

22. Galizia CG, Mcllwrath SL, Menzel R. 1999. A digital three-dimensional atlas of the honeybee antennal lobe based on optical sections acquired by confocal microscopy. Cell Tissue Res. 295:383-94

23. Galizia CG, Menzel R. 2001. The role of glomeruli in the neural representation of odours: results from optical recording studies. F. Insect Pbysiol. 47:115-30

24. Galizia CG, Sachse S, Mustaparta H. 2000. Calcium responses to pheromones and plant odours in the antennal lobe of the male and female moth Heliotbis virescens. F. Comp. Physiol. A 186:1049-63

25. Galizia CG, Szyszka P. 2008. Olfactory coding in the insect brain: molecular receptive ranges, spatial and temporal coding. Entomol. Exp. Appl. 128:81-92 
26. Gibson NJ, Rössler W, Nighorn AJ, Oland LA, Hildebrand JG, Tolbert LP. 2001. Neuron-glia communication via nitric oxide is essential in establishing antennal-lobe structure in Manduca sexta. Dev. Biol. 240:326-39

27. Groh C, Rössler W. 2008. Caste-specific postembryonic development of primary and secondary olfactory centers in the female honeybee brain. Artbropod. Struct. Dev. 37:459-68

28. Guerenstein PG, Hildebrand JG. 2008. Roles and effects of environmental carbon dioxide in insect life. Annu. Rev. Entomol. 53:161-78

29. Hamdani el H, Doving KB. 2007. The functional organization of the fish olfactory system. Prog. Neurobiol. $82: 80-86$

30. Hansson BS, Anton S. 2000. Function and morphology of the antennal lobe: new developments. Annu. Rev. Entomol. 45:203-31

31. Hansson BS, Christensen TA. 1999. Functional characteristics of the antennal lobe. In Insect Olfaction, ed. BS Hansson, pp. 125-61. Berlin/Heidelberg/New York: Springer

32. Hartlieb E, Anderson P, Hansson BS. 1999. Appetitive learning of odours with different behavioural meaning in moths. Physiol. Bebav. 67:671-77

33. Heinrichs V, Ryner LC, Baker BS. 1998. Regulation of sex-specific selection of fruitless $5^{\prime}$ splice sites by transformer and transformer-2. Mol. Cell Biol. 18:450-58

34. Hildebrand JG, Rössler W, Tolbert LP. 1997. Postembryonic development of the olfactory system in the moth Manduca sexta: primary-afferent control of glomerular development. Semin. Cell Dev. Biol. $8: 163-70$

35. Hildebrand JG, Shepherd GM. 1997. Mechanisms of olfactory discrimination: converging evidence for common principles across phyla. Annu. Rev. Neurosci. 20:595-631

36. Hölldobler B, Wilson EO. 1990. The Ants. Cambridge, MA: Belknap. 732 pp.

37. Homberg U, Montague RA, Hildebrand JG. 1988. Anatomy of antenno-cerebral pathways in the brain of the sphinx moth Manduca sexta. Cell Tissue Res. 254:255-81

38. Hoyer SC, LiebigJ, Rössler W. 2005. Biogenic amines in the ponerine ant Harpegnathos saltator: serotonin and dopamine immunoreactivity in the brain. Artbropod. Struct. Dev. 34:429-40

39. Husch A, Pachler M, Fusca D, Paeger L, Kloppenburg P. 2009. Calcium current diversity in physiologically different local interneuron types of the antennal lobe. 7. Neurosci. 29:716-26

40. Ignell R, Anton S, Hansson BS. 2001. The antennal lobe of Orthoptera-anatomy and evolution. Brain Bebav. Evol. 57:1-17

41. Jefferis G, Marin EC, Stocker RF, Luo LQ. 2001. Target neuron prespecification in the olfactory map of Drosopbila. Nature 414:204-8

42. Jefferis GS, Potter CJ, Chan AM, Marin EC, Rohlfing T, et al. 2007. Comprehensive maps of Drosopbila higher olfactory centers: spatially segregated fruit and pheromone representation. Cell 128:1187-203

43. Kanzaki R, Soo K, Seki Y, Wada S. 2003. Projections to higher olfactory centers from subdivisions of the antennal lobe macroglomerular complex of the male silkmoth. Chem. Senses 28:113-30

44. Kelber C, Rössler W, Kleineidam CJ. 2006. Multiple olfactory receptor neurons and their axonal projections in the antennal lobe of the honeybee Apis mellifera. F. Comp. Neurol. 496:395-405

45. Kent KS, Hoskins SG, Hildebrand JG. 1987. A novel serotonin-immunoreactive neuron in the antennal lobe of the sphinx moth Manduca sexta persists throughout postembryonic life. $\mathcal{F}$. Neurobiol. 18:451-65

46. Kirchhof BS, Homberg U, Mercer AR. 1999. Development of dopamine-immunoreactive neurons associated with the antennal lobes of the honey bee, Apis mellifera. 7. Comp. Neurol. 411:643-53

47. Kirschner S, Kleineidam CJ, Zube C, Rybak J, Grunewald B, Rössler W. 2006. Dual olfactory pathway in the honeybee, Apis mellifera. F. Comp. Neurol. 499:933-52

48. Kleineidam C, Tautz J. 1996. Perception of carbon dioxide and other "air-condition" parameters in the leaf cutting ant Atta cephalotes. Naturwissenschaften 83:566-68

49. Kleineidam CJ, Obermayer $M$, Halbich $W$, Rössler W. 2005. A macroglomerulus in the antennal lobe of leaf-cutting ant workers and its possible functional significance. Chem. Senses 30:383-92

50. Kleineidam CJ, Rössler W. 2009. Adaptations in the olfactory system of social hymenoptera. In Organization of Insect Societies: From Genome to Sociocomplexity, ed. J Gadau, J Fewell, pp. 195-219. Cambridge/London: Harvard Univ. Press 
51. Kleineidam CJ, Rössler W, Holldobler B, Roces F. 2007. Perceptual differences in trail-following leafcutting ants relate to body size. F. Insect. Physiol. 53:1233-41

52. Kloppenburg P, Ferns D, Mercer AR. 1999. Serotonin enhances central olfactory neuron responses to female sex pheromone in the male sphinx moth Manduca sexta. 7. Neurosci. 19:8172-81

53. Kondoh Y, Kaneshiro KY, Kimura K, Yamamoto D. 2003. Evolution of sexual dimorphism in the olfactory brain of Hawaiian Drosophila. Proc. Biol. Sci. 270:1005-13

54. Kreiss1 S, Bicker G. 1989. Histochemistry of acetylcholinesterase and immunocytochemistry of an acetylcholine receptor-like antigen in the brain of the honeybee. 7. Comp. Neurol. 286:71-84

55. Krofczik S, Menzel R, Nawrot MP. 2008. Rapid odor processing in the honeybee antennal lobe network. Front. Comput. Neurosci. 2:9

56. Kurtovic A, Widmer A, Dickson BJ. 2007. A single class of olfactory neurons mediates behavioural responses to a Drosophila sex pheromone. Nature 446:542-46

57. Laurent G. 1999. A systems perspective on early olfactory coding. Science 286:723-28

58. Leitch B, Laurent G. 1996. GABAergic synapses in the antennal lobe and mushroom body of the locust olfactory system. f. Comp. Neurol. 372:487-514

59. Linster C, Sachse S, Galizia CG. 2005. Computational modeling suggests that response properties rather than spatial position determine connectivity between olfactory glomeruli. 7. Neurophysiol. 93:3410-17

60. Livingstone $M$, Hubel D. 1988. Segregation of form, color, movement, and depth: anatomy, physiology, and perception. Science $240: 740-49$

61. Lodovichi C, Belluscio L, Katz LC. 2003. Functional topography of connections linking mirrorsymmetric maps in the mouse olfactory bulb. Neuron 38:265-76

62. Malun D, Waldow U, Kraus D, Boeckh J. 1993. Connections between the deutocerebrum and the protocerebrum, and neuroanatomy of several classes of deutocerebral projection neurons in the brain of male Periplaneta americana. 7. Comp. Neurol. 329:143-62

63. Manoli DS, Foss M, Villella A, Taylor BJ, Hall JC, Baker BS. 2005. Male-specific fruitless specifies the neural substrates of Drosophila courtship behavior. Nature 436:395-400

64. Manzini I, Heermann S, Czesnik D, Brase C, Schild D, Rössler W. 2007. Presynaptic protein distribution and odour mapping in glomeruli of the olfactory bulb of Xenopus laevis tadpoles. Eur: 7. Neurosci. 26:92534

65. Manzini I, Rössler W, Schild D. 2002. cAMP-independent responses of olfactory neurons in Xenopus laevis tadpoles and their projection onto olfactory bulb neurons. F. Physiol. 545:475-84

66. Merigan WH, Byrne CE, Maunsell JH. 1991. Does primate motion perception depend on the magnocellular pathway? 7. Neurosci. 11:3422-29

67. Merigan WH, Katz LM, Maunsell JH. 1991. The effects of parvocellular lateral geniculate lesions on the acuity and contrast sensitivity of macaque monkeys. F. Neturosci. 11:994-1001

68. Mobbs PG. 1982. The brain of the honeybee Apis mellifera 1. The connections and spatial organization of the mushroom bodies. Pbilos. Trans. R. Soc. London B Biol. Sci. 298:309-54

69. Müller D, Abel R, Brandt R, Zockler M, Menzel R. 2002. Differential parallel processing of olfactory information in the honeybee, Apis mellifera L. F. Comp. Physiol. A 188:359-70

70. Nagao H, Yoshihara $Y$, Mitsui S, Fujisawa H, Mori K. 2000. Two mirror-image sensory maps with domain organization in the mouse main olfactory bulb. Neuroreport 11:3023-27

71. Nässel DR. 1999. Histamine in the brain of insects: a review. Microsc. Res. Tech. 44:121-36

72. Nässel DR, Homberg U. 2006. Neuropeptides in interneurons of the insect brain. Cell Tissue Res. 326:124

73. Ochieng SA, Poole K, Linn CE Jr, Vickers NJ, Roelofs WL, Baker TC. 2003. Unusual pheromone receptor neuron responses in heliothine moth antennae derived from interspecies imaginal disc transplantation. F. Comp. Physiol. A 189:19-28

74. Pareto A. 1972. Die zentrale Verteilung der Fühlerrafferenz bei Arbeiterinnen der Honigbiene, Apis mellifera L. [Spatial distribution of sensory antennal fibres in the central nervous system of worker bees]. Z. Zellforsch. Mikrosk. Anat. 131:109-40

75. Peele P. 2005. Stable odor coding is ensured by uniglomerular output neurons tbroughout olfactory learning in the boneybee Apis mellifera. $\mathrm{PhD}$ thesis. Freie Univ., Berlin. 84 pp. 
76. Peele P, Ditzen M, Menzel R, Galizia CG. 2006. Appetitive odor learning does not change olfactory coding in a subpopulation of honeybee antennal lobe neurons. 7. Comp. Pbysiol. A 192:1083-103

77. Rehder V, Bicker G, Hammer M. 1987. Serotonin-immunoreactive neurons in the antennal lobes and suboesophageal ganglion of the honeybee. Cell Tissue Res. 247:59-66

78. Rister J, Pauls D, Schnell B, Ting CY, Lee CH, et al. 2007. Dissection of the peripheral motion channel in the visual system of Drosophila melanogaster. Neuron 56:155-70

79. Ro H, Muller D, Mustaparta H. 2007. Anatomical organization of antennal lobe projection neurons in the moth Heliothis virescens. 7. Comp. Neurol. 500:658-75

80. Robertson HM, Wanner KW. 2006. The chemoreceptor superfamily in the honey bee, Apis mellifera: expansion of the odorant, but not gustatory, receptor family. Genome Res. 16:1395-403

81. Rössler W, Oland LA, Higgins MR, Hildebrand JG, Tolbert LP. 1999. Development of a glia-rich axon-sorting zone in the olfactory pathway of the moth Manduca sexta. F. Neurosci. 19:9865-77

82. Rössler W, Randolph PW, Tolbert LP, Hildebrand JG. 1999. Axons of olfactory receptor cells of transsexually grafted antennae induce development of sexually dimorphic glomeruli in Manduca sexta. 7 . Neurobiol. 38:521-41

83. Rössler W, Tolbert LP, Hildebrand JG. 1998. Early formation of sexually dimorphic glomeruli in the developing olfactory lobe of the brain of the moth Manduca sexta. 7. Comp. Neurol. 396:415-28

84. Rössler W, Tolbert LP, HildebrandJG. 2000. Importance of timing of olfactory receptor-axon outgrowth for glomerulus development in Manduca sexta. 7. Comp. Neurol. 425:233-43

85. Royer L, McNeil JN. 1991. Changes in calling behavior and mating success in the European corn borer (Ostrinia nubilalis), caused by relative humidity. Entomol. Exp. Appl. 61:131-38

86. Royer L, McNeil JN. 1993. Effect of relative-humidity conditions on responsiveness of European corn borer (Ostrinia nubilalis) males to female sex pheromone in a wind tunnel. F. Cbem. Ecol. 19:61-69

87. Rybak J, Menzel R. 1993. Anatomy of the mushroom bodies in the honey bee brain: the neuronal connections of the alpha-lobe. 7. Comp. Neurol. 334:444-65

88. Sachse S, Galizia CG. 2006. Topography and dynamics of the olfactory system. In Microcircuits: The Interface Between Neurons and Global Brain Function. Dablem Workshop Report 93, ed. S Grillner, pp. 25173. Cambridge, MA: MIT Press

89. Sachse S, Peele P, Silbering AF, Guhmann M, Galizia CG. 2006. Role of histamine as a putative inhibitory transmitter in the honeybee antennal lobe. Front. Zool. 3:22

90. Sachse S, Rueckert E, Keller A, Okada R, Tanaka NK, et al. 2007. Activity-dependent plasticity in an olfactory circuit. Neuron 56: 838-50

91. Sandoz JC. 2006. Odour-evoked responses to queen pheromone components and to plant odours using optical imaging in the antennal lobe of the honey bee drone Apis mellifera L. F. Exp. Biol. 209:3587-98

92. Sato K, Pellegrino M, Nakagawa T, Vosshall LB, Touhara K. 2008. Insect olfactory receptors are heteromeric ligand-gated ion channels. Nature 452:1002-6

93. Schäfer S, Bicker G. 1986. Distribution of GABA-like immunoreactivity in the brain of the honeybee. 7. Comp. Neurol. 246:287-300

94. Schäfer S, Bicker G, Ottersen OP, Storm-Mathisen J. 1988. Taurine-like immunoreactivity in the brain of the honeybee. 7. Comp. Neurol. 268:60-70

95. Seki Y, Aonuma H, Kanzaki R. 2005. Pheromone processing center in the protocerebrum of Bomlyx mori revealed by nitric oxide-induced anticGMP immunocytochemistry. 7. Comp. Neurol. 481:340-51

96. Sigg D, Thompson CM, Mercer AR. 1997. Activity-dependent changes to the brain and behavior of the honey bee, Apis mellifera (L.). 7. Neurosci. 17:7148-56

97. Silbering AF, Galizia CG. 2007. Processing of odor mixtures in the Drosophila antennal lobe reveals both global inhibition and glomerulus-specific interactions. 7. Neurosci. 27:11966-77

98. Silbering AF, Okada R, Ito K, Galizia CG. 2008. Olfactory information processing in the Drosopbila antennal lobe: Anything goes? 7. Neurosci. 28:13075-87

99. Stange G, Stowe S. 1999. Carbon-dioxide sensing structures in terrestrial arthropods. Microsc. Res. Tech. $47: 416-27$

100. Steinbrecht RA. 1996. Structure and function of insect olfactory sensilla. Ciba Found. Symp. 200:158-74

101. Stocker RF. 1994. The organization of the chemosensory system in Drosophila melanogaster: a review. Cell Tissue Res. 275:3-26 
102. Stocker RF, Lienhard MC, Borst A, Fischbach KF. 1990. Neuronal architecture of the antennal lobe in Drosophila melanogaster. Cell Tissue Res. 262:9-34

103. Stockinger P, Kvitsiani D, Rotkopf S, Tirian L, Dickson BJ. 2005. Neural circuitry that governs Drosopbila male courtship behavior. Cell 121:795-807

104. Strausfeld N. 2009. Brain organization and the origin of insects: an assessment. Proc. R. Soc. London B Biol. Sci. 276:1929-37

105. Strausfeld NJ, Sinakevitch I, Brown SM, Farris SM. 2009. Ground plan of the insect mushroom body: functional and evolutionary implications. 7. Comp. Neurol. 513:265-91

106. Strausfeld NJ, Sinakevitch I, Vilinsky I. 2003. The mushroom bodies of Drosopbila melanogaster: an immunocytological and Golgi study of Kenyon cell organization in the calyces and lobes. Microsc. Res. Tech. 62:151-69

107. Suh GS, Wong AM, Hergarden AC, Wang JW, Simon AF, et al. 2004. A single population of olfactory sensory neurons mediates an innate avoidance behavior in Drosopbila. Nature 431:854-59

108. Suzuki H. 1975. Convergence of olfactory inputs from both antennae in the brain of the honeybee. 7. Exp. Biol. 62:11-26

109. Syed Z, Leal WS. 2007. Maxillary palps are broad spectrum odorant detectors in Culex quinquefasciatus. Chem. Senses 32:727-38

110. Syed Z, Leal WS. 2008. Mosquitoes smell and avoid the insect repellent DEET. Proc. Natl. Acad. Sci. USA 105:13598-603

111. Tanaka NK, Awasaki T, Shimada T, Ito K. 2004. Integration of chemosensory pathways in the Drosophila second-order olfactory centers. Curr. Biol. 14:449-57

112. Vosshall LB, Stocker RF. 2007. Molecular architecture of smell and taste in Drosophila. Annu. Rev. Neurosci. 30:505-33

113. Wanner KW, Nichols AS, Walden KK, Brockmann A, Luetje CW, Robertson HM. 2007. A honey bee odorant receptor for the queen substance 9-oxo-2-decenoic acid. Proc. Natl. Acad. Sci. USA 104:14383-88

114. Wegerhoff R. 1999. GABA and serotonin immunoreactivity during postembryonic brain development in the beetle Tenebrio molitor. Microsc. Res. Tech. 45:154-64

115. Wicher D, Schafer R, Bauernfeind R, Stensmyr MC, Heller R, et al. 2008. Drosopbila odorant receptors are both ligand-gated and cyclic-nucleotide-activated cation channels. Nature 452:1007-11

116. Wilson RI, Mainen ZF. 2006. Early events in olfactory processing. Annu. Rev. Neurosci. 29:163-201

117. Winnington AP, Napper RM, Mercer AR. 1996. Structural plasticity of identified glomeruli in the antennal lobes of the adult worker honey bee. F. Comp. Neurol. 365:479-90

118. Xu P, Atkinson R, Jones DN, Smith DP. 2005. Drosopbila OBP LUSH is required for activity of pheromone-sensitive neurons. Neuron 45:193-200

119. Zube C, Kleineidam CJ, Kirschner S, Neef J, Rössler W. 2008. Organization of the olfactory pathway and odor processing in the antennal lobe of the ant Camponotus floridanus. F. Comp. Neurol. 506:425-41

120. Zube C, Rössler W. 2008. Caste- and sex-specific adaptations within the olfactory pathway in the brain of the ant Camponotus floridanus. Artbropod. Struct. Dev. 37:469-79 